\title{
Greater Temperature and Precipitation Extremes Intensify Western U.S. Droughts, Wildfire Severity, and Sierra Nevada Tree Mortality
}

\author{
JoSEPH L. CROCKETT AND A. LEROY WESTERLING \\ University of California, Merced, Merced, California
}

(Manuscript received 18 April 2017, in final form 21 August 2017)

\begin{abstract}
Extensive drought in the western United States (WUS) during the twenty-first century and associated wildfire and tree mortality incidence has highlighted the potential for greater area of severity within widespread droughts. To place recent WUS droughts into a historical context, the authors analyzed gridded daily climate (temperature, precipitation, and climatic water deficit) data to identify and characterize the spatiotemporal evolution of the largest WUS droughts of the last 100 years, with an emphasis on severe cores within drought extents. Cores of droughts during the last 15 years (2000-02 and 2012-14) covered a greater area than in earlier droughts, driven by greater temperature and precipitation extremes. Comparing fire extent and severity before, during, and after drought events using the monitoring trends in burn severity dataset (1984-2014), the authors found fire size and high-severity burn extent were greater during droughts than before or after. Similarly, recent Sierra Nevada forest mortality was greatest in cores immediately after the drought. Climate simulations anticipate greater extremes in temperature and precipitation in a warming world; droughts and related impacts of the last 15 years may presage the effects of these extremes.
\end{abstract}

\section{Introduction}

Western U.S. (WUS) droughts may intensify with increasing temperatures and more variable precipitation as climate changes (Diffenbaugh et al. 2015; Ault et al. 2014). Presaging this future, the 2012-14 (and to a lesser extent 2000-03) droughts were characterized by temperature and precipitation extremes, with severe consequences for vegetation, water supplies, agriculture, and wildfire risk (Guarín and Taylor 2005; Howitt et al. 2014; Parks et al. 2016). Although 2012-14 conditions were unprecedented in the instrumental climate record, severe droughts occur periodically in the WUS (Griffin and Anchukaitis 2014). However, comparisons of spatiotemporal climate patterns over the formation, progression, and termination of regional, multiyear WUS droughts remain scarce. Recent work offers substantive comparisons of droughts and effects, but these and similar studies can be spatially or temporally limited or use indicators unsuited to assessing ecological impacts or long-term trends (Bachmair et al. 2016; Robeson 2015; Ge et al. 2016; Asner et al. 2016).

\footnotetext{
Corresponding author: Joseph L. Crockett, jcrockett@ucmerced. edu
}

Large-scale circulation patterns linked to global climate phenomena (e.g., ENSO, PDO, and AMO) drive drought severity and extent, while local factors like topography modulate drought signatures (McCabe et al. 2004). In the west, highly variable climate, particularly precipitation, produces periodic interannual to decadal droughts (Cook et al. 2007; Routson et al. 2016; Griffin and Anchukaitis 2014). Large interannual droughts can arise when conditions redirect storm paths over an extended period, with large ecosystem effects. For example, during the 2012 California drought, ENSO precursors developed into a persistent pressure ridge that redirected precipitation northward (Wang et al. 2014), resulting in progressive canopy water loss in $10+$ million ha of forest (Asner et al. 2016). In the southwestern United States in the 1950s and 2000s, high temperatures and disruption of summer precipitation exacerbated atmospheric moisture demand during droughts (Weiss et al. 2009), accompanied by greater rates of piñon pine mortality (Mueller et al. 2005) and bark beetle outbreaks (Shaw et al. 2005).

While ecosystems adapt to and arise from local longterm climate averages and variability, tolerance of seasonal drought in the arid West does not ensure survival 
during prolonged events (McDowell et al. 2008). Species adapted to mesic environments tend toward greater mortality during droughts, but survival of droughttolerant species also decreases under severe and lengthy droughts (McDowell et al. 2008). Tree mortality due to drought stress, particularly during warmer periods, may result from hydraulic failure or carbon starvation, or indirectly through increased susceptibility to wildfire or biotic attack. Growing consensus indicates that greater tree mortality is occurring globally during "hot droughts" (Allen et al. 2010; van Mantgem et al. 2009; Williams et al. 2013; Cook et al. 2014; Donat et al. 2016). These conditions are also conducive to wildfire. While there is considerable diversity in climate-wildfire interactions across western U.S. forests, high spring and summer temperatures coupled with previous-year or year-of drought commonly drive regional variations in large wildfire incidence and extent through fuel effects (Westerling et al. 2003; Westerling et al. 2006; Heyerdahl et al. 2008; Morgan et al. 2008; Littell et al. 2009; Westerling 2016). However, commonly used drought indicators pose challenges to assessing the temperatureseverity relationship (Williams et al. 2013).

Limitations in drought metrics are unavoidable: severity is subjective beyond "dry" (Alley 1984; Bachmair et al. 2016). Stakeholder-specific thresholds identifying extreme aridity must be established, as drought indicators useful for one application may not be relevant to another (Steinemann et al. 2005; Stephenson 1998; Steinemann 2014; Bachmair et al. 2015). Optimal definitions of drought duration can be subjective (Ge et al. 2016): short durations may fail to differentiate seasonal climatological drought occurrence that ecosystems are adapted to from prolonged events with ecological significance. Alternatively, filtering for long duration may register "megadroughts" with decadal-scale duration but obscure shorter droughts characteristic of the twentieth century (Cook et al. 2007).

Development of quantitative drought metrics that 1) capture the spatial scale of interannual droughts, 2) adjust for regional climate, topography, and demand, and 3) can be applied by a wide range of stakeholders is ongoing (Steinemann 2014). Indicators attempt to characterize the water balance of a location or region using available moisture supply and demand relative to a base period. The standardized precipitation index (SPI), standardized precipitation evapotranspiration index (SPEI), Palmer drought severity index (PDSI), and others are widely used indicators (Bachmair et al. 2016) that work over large regions and can be calculated using few variables. However, their reliance on precipitation to dictate moisture supply may reduce their usefulness when considering ecological effects (Stephenson 1998; Crausbay et al. 2017). Consequently, a full accounting of the water balance is necessary to assess ecological effects (Stephenson 1990, 1998; Lutz et al. 2010; Crausbay et al. 2017).

Drought indicators are commonly classified by drought type: streamflow- or water-level-based indicators for hydrological drought; precipitation and related water balance indicators for meteorological droughts; crop moisture or measures of greenness for agricultural droughts; and municipal water shortage indicators for socioeconomic droughts. Among the multitude of indicators, selection of an indicator depends on the investigator and available data.

For the work reported here, we wanted to employ an ecologically meaningful index that integrates precipitation and temperature effects on available moisture and to compare the relative contributions of temperature and precipitation to the formation, persistence, and severity of major western U.S. droughts. Commonly used drought indicators are not well suited to this purpose. SPI does not incorporate temperature. PDSI does use temperature, but it is still primarily a precipitation index. SPEI addresses some of the inadequacy of SPI by calculating an index based on the difference between precipitation and potential evapotranspiration. The difference between precipitation and potential evapotranspiration has been shown however to have less power to predict spatial patterns in the occurrence of ecosystem types than climatic water deficit and actual evapotranspiration (Stephenson 1990, 1998).

Ecological drought has recently been proposed as a fifth drought metric classification, though discussion of its boundaries is ongoing (Crausbay et al. 2017). In contrast to other drought classifications, ecological drought metrics attempt to describe abnormal departures from moisture conditions when accounting for local ecosystems without a human-specific viewpoint of drought effects. Ecological drought metrics identify droughts on longer time and larger spatial scales that have the potential to shift ecosystems - as well as human systems - past their adaptive capacity (Crausbay et al. 2017). Addressing the prevalence of ecologically significant droughts in the twentieth and twenty-first centuries requires a metric suited to addressing long-term ecosystem trends.

Cumulative standardized climate water deficit (CWD) is a suitable metric to assess ecological drought because of its strong links to vegetation distribution and temperature, applicability across spatial scales, and interpretability (Stephenson 1998; Lutz et al. 2010). 
CWD measures water imbalance and indicates cumulative unmet evaporative demand. Prolonged anomalous CWD can be interpreted as accumulated abnormal drying (as in Stephenson 1998). CWD incorporates soil, vegetation, temperature, precipitation, relative humidity, and preceding conditions; thus, it is interpretable by stakeholders concerned with available precipitation (meteorological drought), moisture available for transpiration (agricultural drought), and moisture available as runoff (hydrological drought). CWD is sensitive to temperature, allowing assessment of effects of low precipitation coupled with rising temperatures during prolonged droughts (Stephenson 1998).

Use of CWD as an ecologically meaningful drought indicator is also supported by strong links between CWD and ecological disturbance. Van Mantgem et al.(2009) found increasing background tree mortality in western U.S. forests, and van Mantgem and Stephenson (2007) associated Sierra Nevada tree mortality with increasing CWD due to warming. Westerling (2009) showed that cumulative standardized climatic water deficit is an indicator of fire risk that varies with vegetation type. Changes in CWD explain more than $90 \%$ of the spatial variability in changes in large forest fire occurrence associated with recent changes in timing of western U.S. spring snowmelt (Westerling 2016). Increased mountain pine beetle populations were determined by Creeden et al. (2014) to coincide with droughts defined in terms of CWD in the WUS. Westerling et al. (2011a,b), Liang et al. (2017a,b), and Keyser and Westerling (2017) tested multiple statistical model specifications using a variety of climate and land surface variables to predict wildfire occurrence, size, and severity, with CWD the primary common climatic predictor for fire activity across these modeling efforts.

We ask here if the incidence of severe and extremely severe drought area within larger regional droughts has changed between 1918 and 2014. To address this and to place recent WUS drought in a long-term context, we compare areas of severe drought across the last century, examining trends in drought severity measured by CWD. To illustrate how temperature and precipitation contributions to droughts vary over time, we disaggregate their influences on CWD over the course of six large droughts of the past century, with a specific focus on regions of extreme drought severity. Finally, we examine the effects of drought on wildfire size/severity and recent California tree mortality to understand relationships between severe drought and secondary effects.

\section{Methods}

a. Data

\section{1) LAND COVER AND GRIDDED HYDROLOGICAL DATA}

We obtained $1 / 8^{\circ}$ gridded daily climate data (temperature and precipitation over $31^{\circ}-49^{\circ} \mathrm{N}$ and $102^{\circ}-125^{\circ} \mathrm{W}$ ) derived from historical observations (1915-2014) using the index station method from the National Hydrologic Prediction System (NHPS) (Wood and Lettenmaier 2006). NHPS also provided daily simulations from the Variable Infiltration Capacity hydrologic model (VIC$3 \mathrm{~L}$ ) in water balance mode forced with gridded temperature and precipitation, fractional North American Land Data Assimilation System vegetation and topography, and climatological winds from NCEP reanalysis (Liang et al. 1994; Mitchell et al. 2004). VIC-3L simulations returned actual evapotranspiration (AET). We estimated potential evapotranspiration (PET) from daily maximum and minimum temperature via the Penman-Monteith equation with the same forcing data (Penman 1948; Monteith 1965) and calculated CWD = PET - AET (Stephenson 1990). Monthly means (sums) were calculated for temperature (CWD and precipitation). We calculated October-September aggregates of each variable to capture the seasonality of water in the western United States.

NHPS data end in 2014. To capture the full time series of the 2012 drought evolution, both before and after the drought, we obtained 2015 and earlier temperature and precipitation from the Livneh daily $1 / 16^{\circ}$ meteorological dataset (Livneh et al. 2015) in order to extend our dataset by 1 year. We aggregated these to monthly values at the resolution of the VIC-3L variables $\left(1 / 8^{\circ}\right)$. The CWD was simulated using the generalized additive model (GAM) discussed below. Correlations were strong between historical $1 / 8^{\circ}$ VIC and rescaled Livneh data for monthly precipitation (0.920), temperature (0.995), and CWD (0.939). The data for our analysis use the NHPS and VIC-3L data through 2014 and the values derived from Livneh for 2015.

Palmer and others (e.g., Andreadis et al. 2005) note the importance of standardizing or normalizing variables over time and space to facilitate comparisons between distinct time periods and locations. Normalization ensures that locations and times with distinct climatologies are comparable as standardized anomalies. We normalized variables at each voxel using its 1918-2014 mean and standard deviation ( $z$ score):

$$
z=\frac{X-\mu}{\sigma},
$$


TABLE 1. Generalized additive models utilize a variety of subroutines to estimate smoothing as models are fit to terms. The MGCV package, developed and maintained by Simon Wood, uses as default a penalized maximum likelihood to select smoothing parameters, though users can designate specific smooths. Smoothing functions are iteratively generated as the model is built. In contrast to linear functions, a matrix of coefficients is created rather than a single coefficient per term. REML indicates a restricted maximum likelihood method.

\begin{tabular}{llll}
\hline \hline \multicolumn{1}{c}{ Variable } & \multicolumn{1}{c}{ Description } & Smoothing term & Method \\
\hline Temperature & Monthly mean temp & Thin plate regression spline & Fast REML \\
Precipitation & Monthly cumulative precipitation & Thin plate regression spline & Fast REML \\
Lon, lat, month & Interaction term between & Tensor product smooths with Duchon & Fast REML \\
& location and time of year & spline (lon, lat) and cubic cyclic spline (month) & \\
\hline
\end{tabular}

where $z$ is a voxel's value $X$ reported in terms of standard deviations $\sigma$ away from the mean $\mu$. We used R, version 3.4.0, with the dplyr, ggplot2, raster, sp, rgdal, and reshape 2 packages to conduct analysis and plot figures (Bivand et al. 2017; Hijmans 2016; Pebesma and Bivand 2005; R Development Core Team 2011; Wickham and Francois 2016; Wickham 2009, 2007).

\section{2) FIRE SEVERITY DATA}

Fire records between 1 January 1984 and 31 December 2014 were accessed from the Monitoring Trends in Burn Severity (MTBS) project (MTBS 2016). MTBS assesses burn area and severity from pre- and postdisturbance satellite imagery (Eidenshink et al. 2007) for large ( $>400$ ha) wildfires. The semiautomated program identifies fire perimeters, assigns a location based upon available records or central mass, and calculates the differential normalized burn ratio (dNBR) between imagery prior to and up to a year later. Fires are designated by type: wild, prescribed, or wild land use. We excluded the latter two classes as these are controlled burns whose perimeter is more strictly defined by fire management. The resultant dataset included 7742 fires between 1984 and 2014. We assigned each fire to the grid cell with greatest burned area coverage per fire to develop a $1 / 8^{\circ}$ gridded fire history (Keyser and Westerling 2017).

Severity classifications are "increased greening," "no change," "low severity," "moderate severity," "high severity," and "no value." We excluded pixels of increased greenness, no value, and no change, instead focusing on the three remaining severity designations. We calculated each as a percentage of the burned area.

\section{3) TRee MORTAlity DATA}

We obtained 2.5-min aerial detection survey (ADS) counts of tree mortality (2004-16) processed by Preisler et al. (2017) for California. ADS surveys tree mortality from bark beetles, wood borers, and drought annually by air (Young et al. 2017). We aggregated tree mortality to our $1 / 8^{\circ}$ grid. We compared mortality before, during, and after the 2012-14 drought using the nonparametric Kruskal-Wallis (KW) test by ranks between groups to determine significant shifts in distributions and extremes. Subsequently, we conducted post hoc pairwise multiple comparisons between groups using Dunn's test of multiple comparison by ranks using the dunn.test package in $\mathrm{R}$ (Dinno 2017).

\section{b. Drought analysis}

\section{1) SELECTION OF SEVERITY AND DURATION THRESHOLDS FOR DROUGHT CORE IDENTIFICATION}

We hypothesized that within larger regional drought exist "cores" of persistent greater severity. To distinguish cores from larger drought affected areas, we compared combinations of duration and severity. Standardized wateryear CWD (1 October through 30 September) was used to classify pixels as a drought core if they met or exceeded a threshold $(0.5,1$, and 2 standard deviations above the 19182014 mean CWD) for a specified duration (2, 3, and 5 years). A combination of duration and severity was selected that reduced years of small drought core area while retaining a core centered on California beginning 2012.

\section{2) Modeled INFLUENCE OF TEMPERATURE AND PRECIPITATION}

We developed a GAM to analyze effects of temperature and precipitation on CWD. GAMs are a nonparametric extension of generalized linear models. They are particularly useful in characterizing nonlinear relationships between response and covariates. Models were built using the BAM function of the mixed GAM computational vehicle (MGCV) package in $\mathrm{R}$ (R Development Core Team 2011; Wood 2011) such that

$$
\begin{aligned}
g[E(\mathrm{CWD})]= & \beta_{0}+f_{1}(\text { precipitation })+f_{2}(\text { temperature }) \\
& +f_{3}(\text { lat }, \text { lon }, \text { month }),
\end{aligned}
$$

where $\beta_{0}$ is the model coefficient and $g[E(\mathrm{CWD})]$ denotes the link function relating the expected value of CWD to the predictor variables $f_{1}$ (precipitation), $f_{2}$ (temperature), and $f_{3}$ (lat, lon, month), with $f_{k}$ representing nonparametric 


\section{Drought Core Occurrence, 1918 to 2014}
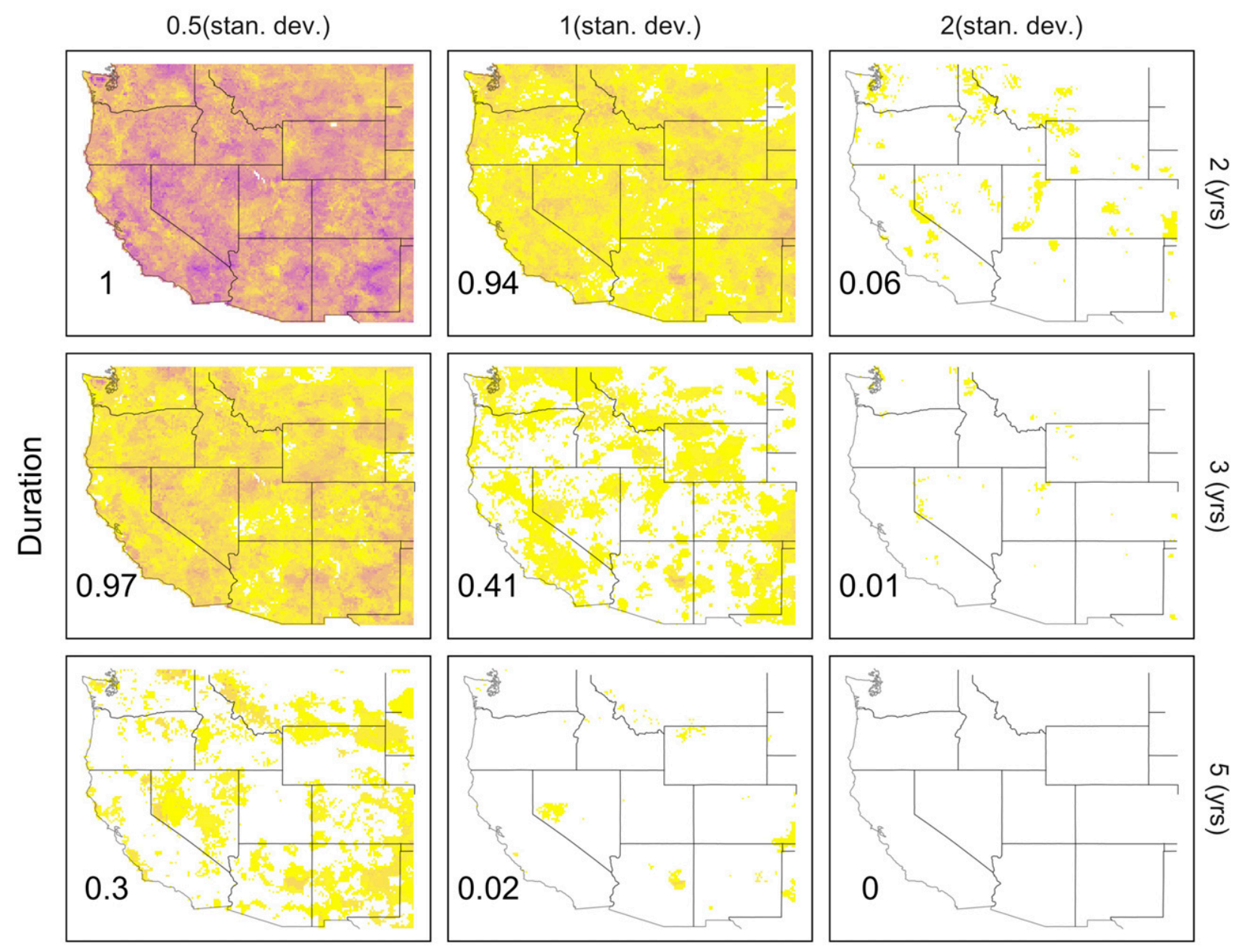

Severity Threshold

Occurrences (1918 to 2014)

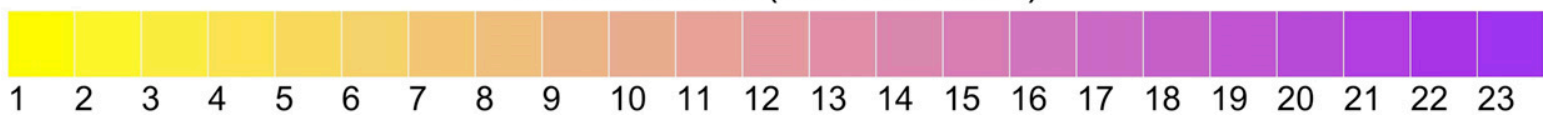

FIG. 1. Spatial footprints of droughts are plotted by duration/threshold combination, 1918-2014. The location and frequency of drought occurrences are indicated by the color gradient. Area covered by drought (expressed as a fraction of WUS area) is shown in the bottomleft corner of the panels. Our intention was to determine a combination of duration and threshold severity that reveals low drought frequency while retaining spatially extensive signals. This was best represented by a 3-yr duration and one-standard-deviation threshold, shown by the center panel.

smooth functions estimated by restricted maximum likelihood (REML) (Table 1). The model was fit to $75 \%$ of the data, leaving the remaining $25 \%$ for validation. A number of smoothing functions representing tradeoffs between a selected level of smoothing and allowed degrees of freedom are available. A tensor smoother was applied to the spatial term as suggested by Aalto et al. (2013) and Wood (2006), while a cubic cyclic spline fit to month accounted for seasonality. Because CWD is calculated from precipitation and temperature, we expected explained variance to be high and did not include other terms. We selected a GAM $\left(r^{2}=0.89\right.$; correlation coefficient $\left.=0.944\right)$ with separated terms to distinguish the influence of temperature versus precipitation on monthly CWD during droughts (Wood 2006). To show accumulated effects, we cumulated temperature and precipitation influences 


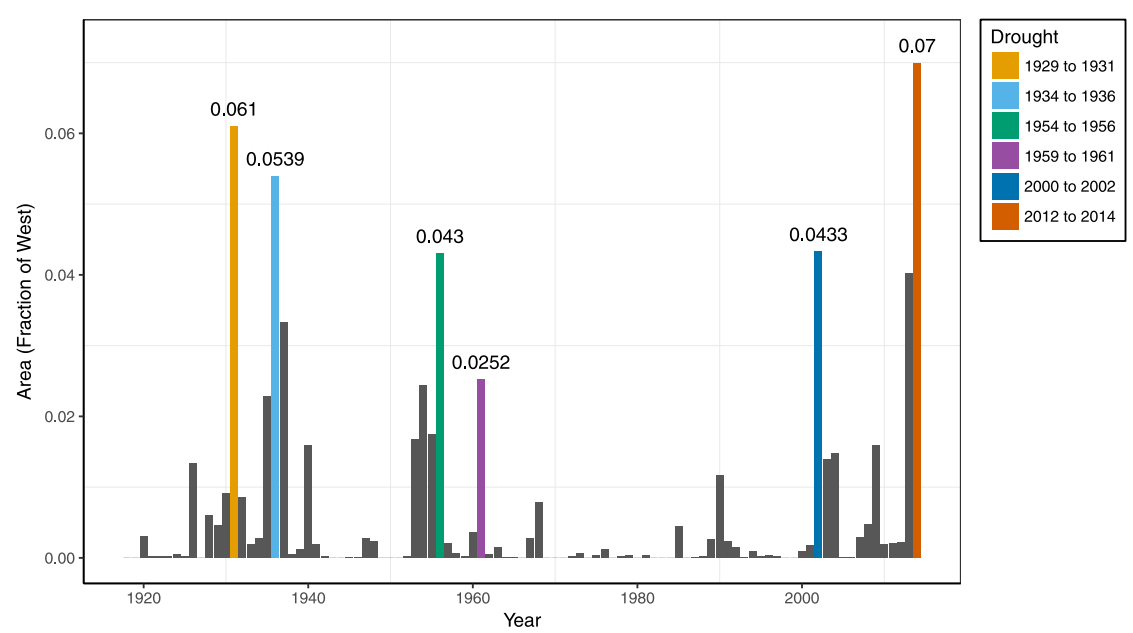

FIG. 2. Drought area by year using a 3 -yr duration and one-standard-deviation severity threshold is plotted by the third year identity. The $x$ axis is in years and the $y$ axis indicates drought cover for a given year (fraction of region). Bars are positioned on the third year of the drought window. Six droughts were selected for further analysis from three distinct periods: the 1930s, the 1950s, and the 2000s. Drought areas for these six droughts are indicated by the fraction above the colored bars.

over 36 months. To identify severe drought regions, we calculated the cumulative sums of CWD over 36 months (CWD36). We set an additional extreme severity threshold as the 95th percentile of the CWD36 over the six largest droughts. To avoid confusion, we refer to pixels identified by the initial drought threshold as "drought cores" or "cores" and this second, extreme threshold as "extreme drought locations."

\section{3) High-SEVERITY FIRE MODELS}

MTBS classifies 30-m pixels within fire perimeters into six severity classes: unburned to low, low, moderate, high, increasing greenness, and cloud cover/error. We categorized fires as "before," "during," or "after" if they 1) occurred within a drought core and 2) occurred in the preceding three years, during the 3-yr drought window, or in the following three years, respectively. The "after" class does not include post-2014 fires. We included fires from all drought grid cells (1984-2014) to extend the dataset. We compared fire size and fractions of fires that burned at low, medium, and high severity using KW tests followed by post hoc Dunn's tests between groups to determine significant shifts in distributions and extremes.

\section{Results}

It is important to note that drought cores are not bound by strict delineations but are rather surrounded by decreasing levels of moisture deficit/stress. Here, we identified core areas within larger continuous droughts that were continuously dry for multiyear periods. We found no cores at the most severe/longest duration [2 standard deviations $(5 \mathrm{yr})^{-1}$ ], while cores occurred in the entire spatial domain at the lowest severity/shortest duration $\left[0.5\right.$ standard deviations $\left.(2 \mathrm{yr})^{-1}\right]$ (Fig. 1$)$. We searched for spatial continuity in cores that balanced the signal (condensed cores) to noise (widely distributed cores) ratio. At lower thresholds, core areas were larger and more numerous interannually. As thresholds rose, core area concentrated and fewer years experienced cores within larger drought areas. Our preferred threshold balanced core area with number of years with identified cores. The ideal parameters would be selective while balancing large enough cores to generate climate statistics. This selective threshold highlights the spatial and temporal complexity of extreme droughts within larger continuous regions of droughts (Fig. 3, below). In doing so, we note that greater area of extreme drought occurred in 2012 to 2014.

We selected parameters of one standard deviation and 3-yr duration for further analysis (Fig. 2). The six severe droughts cores identified represent different ecoregions and time periods, although some overlap occurred: the Pacific Northwest, 1929-31; northern Rockies, 1934-36; Southwest, 1954-56; interior, 1959-61; southern Rockies, 2000-02; and Great Basin and California, 2012-14 (Fig. 3). The 3-yr drought core area was greatest in 201214 (7\% of the WUS), followed by $1929-31$ ( $6.1 \%$ of the WUS) and 1934-36 (5.39\% of the WUS). While drought cores could be spatially distinct (Fig. 3, panel labeled "1959 to 1961"), they were linked by extensive regional droughts. 


\section{Selected Droughts}
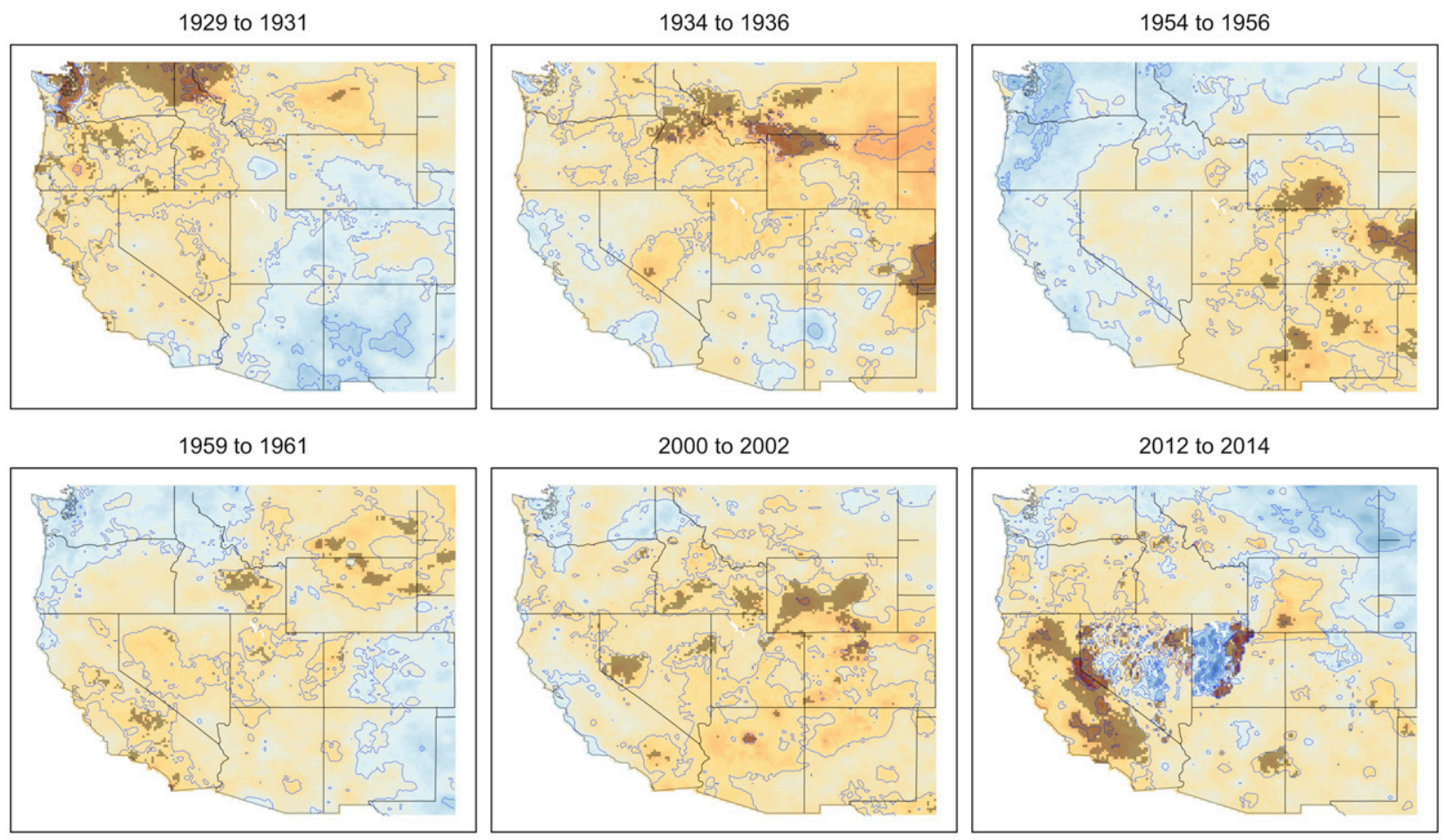

Three Year Climatic Water Deficit

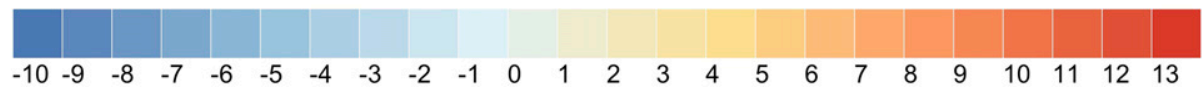

FIG. 3. Spatial footprints of selected drought cores (gray) are plotted against annual climatic water deficit anomalies accumulated for three years. Blue (yellow) show areas that grew wetter (dryer) by the third year. Drought cores are identified by pixels in which the annual climatic water deficit anomaly exceeded one standard deviation above the 1918-2014 mean for three consecutive years.

Patterns across drought cores included depressed precipitation relative to preceding and/or following years (Figs. 4a,c). The first drought year was often characterized by elevated temperatures, which subsequently declined, excepting the 2012-14 drought, which started high and rose through 2015 (Fig. 4b). Parts of the 1934-36 and 2012-14 droughts appeared to extend into a fourth year: nearly $54 \%$ of both drought cores exceeded one standard deviation CWD following the drought (in 1937 and 2015, respectively). Furthermore, 1937 is characterized by depressed precipitation, though temperature fell below the longterm average from a significantly high first drought year. In contrast, 2015 is characterized by near-normal precipitation and a continuing high temperature trend that began in the first drought year. In $2003,37 \%$ of the 2000-02 drought core area was as severe as 2002 and characterized by depressed precipitation and high temperature. Table 2 summarizes atmospheric drivers associated with drought variability and strength during the selected drought cores.

Precipitation contributions to CWD were similar between drought cores, though median values differed (KW test; $p$ value $<0.01$; Fig. 5a). Temperature contributions were more variable and roughly comparable to the mean temperature experienced in droughts; that is, high temperatures corresponded with high temperature contribution to CWD (Figs. 4 and 5a). Both temperature and precipitation contributions in 2012-14 exceed other drought cores, especially considering the number and range of outliers (KW test; $p<0.01 ; p<$ 0.01) (Fig. 5a). Note that the spread of temperature and precipitation contributions to CWD differs significantly between droughts, from a near-neutral accumulated temperature contribution during 1929-31 to wider spreads in conditions across the 1934-36, 200002, and 2012-14 droughts. These differences are magnified in the most severe regions of each drought core 


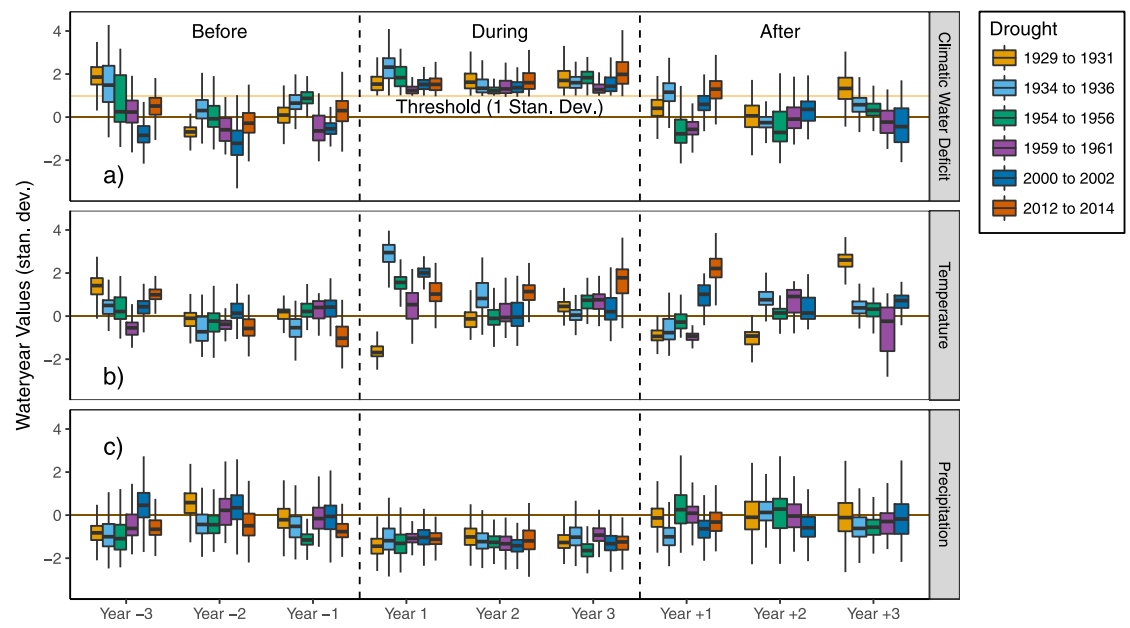

FIG. 4. Water year standardized (a) CWD, (b) temperature, and (c) precipitation in drought footprints are plotted before, during, and after selected drought events. Year -3 on the $x$ axis corresponds to three years before the beginning of the drought, while year +3 corresponds to the third year following the end of the drought. Box plots describe the 25th-75th percentile with medians shown by black horizontal lines and colored by drought. Whiskers are within 1.5 times the interquartile range (IQR). The 2012-14 box (orange) in year +1 indicates the added values from the Livneh meteorological dataset described in the text.

(Fig. 5b). Imposing an even stricter threshold upon the selected drought cores consequently establishes extreme drought locations within the larger drought core. Though similar in spatial extent (Fig. 3), earlier extreme drought locations are characterized by smaller variance of temperature and precipitation contributions (Fig. 5a) as well as smaller area, relative to 201214 (Fig. 5b). The extreme 2012-14 drought locations have median temperature (precipitation) contributions $35 \%(102 \%)$ greater than earlier extreme droughts locations, with extreme locations affecting a much larger area (Figs. 5b,c). The most severe instances were seen in the Sierra Nevada and Wasatch Range, highlighting the impact of sustained severe drought in watersheds (Cayan et al. 2001; Udall and Overpeck 2017) (Figs. 3 and 5b).

TABLE 2. Relationships between local conditions and global circulation patterns are indicated as drivers of regional drought occurrence. This table describes external drivers of droughts from the literature during periods covering the selected droughts shown in Fig. 3.

\begin{tabular}{|c|c|c|}
\hline Drought period & Driver & Sources \\
\hline $1930 \mathrm{~s}$ & $\begin{array}{l}\text { Sea surface temperature anomalies and dust } \\
\text { interactions, positive Pacific decadal } \\
\text { oscillation (PDO)/positive North Atlantic } \\
\text { Oscillation (NAO), natural weather } \\
\text { variability, and weakening of Great Plains } \\
\text { low-level jet stream. }\end{array}$ & $\begin{array}{l}\text { Cook et al. (2011), McCabe et al. (2004), } \\
\text { Brönnimann et al. (2009), Cook et al. (2008), } \\
\text { Schubert et al. (2004), and Hoerling et al. (2009) }\end{array}$ \\
\hline $1950 \mathrm{~s}$ & $\begin{array}{l}\text { Sea surface temperature anomalies (cool } \\
\text { east Pacific/warm west Pacific) and negative } \\
\text { PDO/positive AMO. }\end{array}$ & $\begin{array}{l}\text { Seager and Hoerling (2014), Hoerling et al. (2009), } \\
\text { Rajagopalan et al. (2000), and McCabe et al. (2004) }\end{array}$ \\
\hline $2000 \mathrm{~s}$ & $\begin{array}{l}\text { Sea surface temperature anomalies (cool } \\
\text { east Pacific/warm west Pacific) } \\
\text { associated with increased temperature } \\
\text { in intermountain west/southwest, } \\
\text { decreased precipitation in intermountain } \\
\text { west/central Pacific coast, and negative } \\
\text { PDO/positive NAO. }\end{array}$ & $\begin{array}{l}\text { Seager and Hoerling (2014), McCabe et al. (2004), } \\
\text { Hoerling and Kumar (2003), and Rajagopalan et al. } \\
\text { (2000) }\end{array}$ \\
\hline $2010 \mathrm{~s}$ & $\begin{array}{l}\text { Atmospheric pressure anomalies along WUS } \\
\text { coastline associated with ENSO precursors and } \\
\text { atmospheric internal dynamics. }\end{array}$ & $\begin{array}{l}\text { Teng and Branstator (2017), Hoerling et al. (2014), and } \\
\text { Wang et al. (2014) }\end{array}$ \\
\hline
\end{tabular}


a) Month 36 Contribution to CWD in Selected Droughts

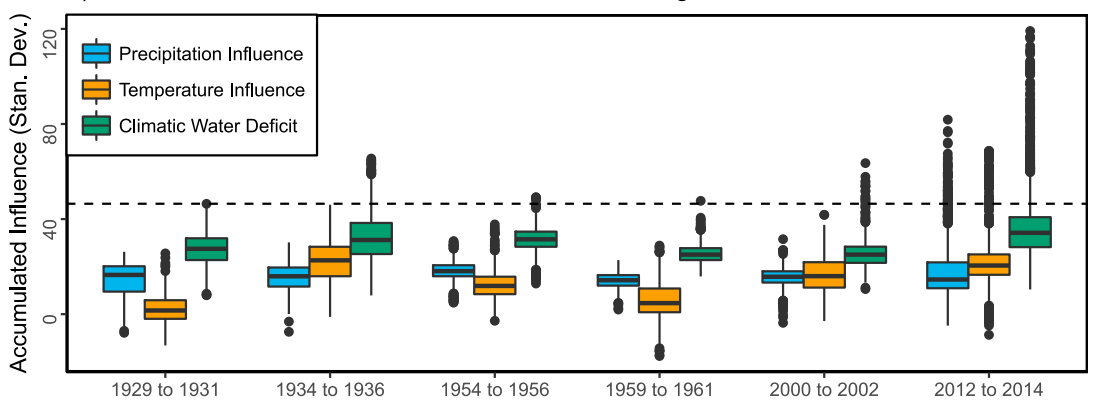

c) Month 36 Contribution to CWD, Extreme Regions

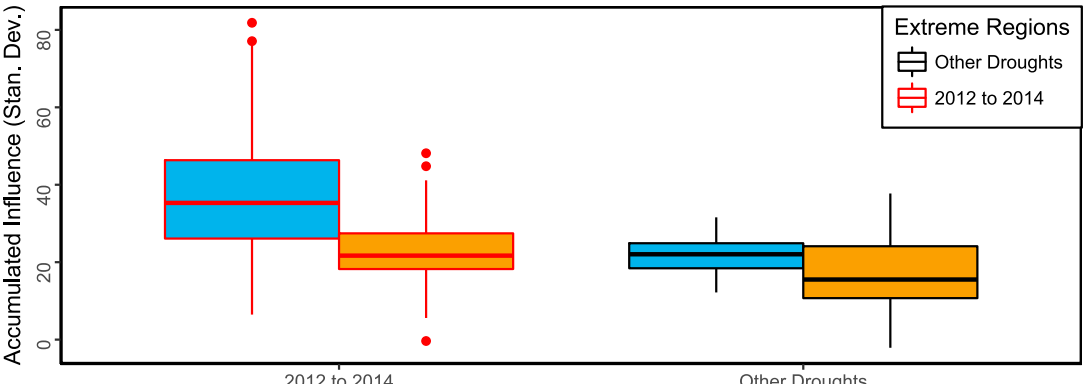

b) Extreme Drought Regions
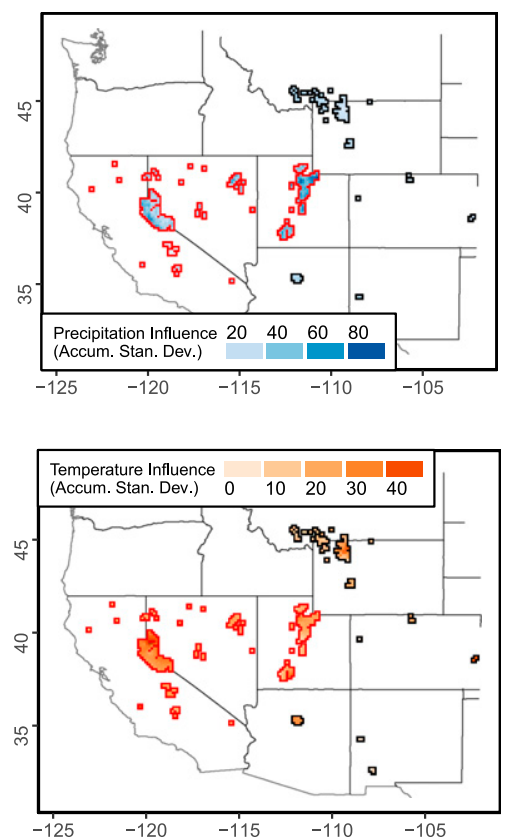

FIG. 5. The accumulated relative monthly contributions of precipitation and temperature to CWD are plotted at the final month of drought. (a) Box-and-whisker plots of the 36-month precipitation contributions (PI36), temperature contributions (TI36), and CWD (CWD36) in selected droughts. Box plots describe the 25th-75th percentile with medians shown by black horizontal lines and colored by drought. Whiskers are within $1.5 \times$ IQR. The dashed horizontal line indicates a single extreme severity threshold, calculated as the 95th percentile of the CWD36 from the six selected droughts. (b) The extreme drought area, with 2012-14 extreme severity outlined in red and other droughts outlined in black. (c) Box-and-whisker plots of PI36 and TI36 in the extreme drought areas with colors corresponding to box plot colors in (a).

Total and high-severity burned areas were greater during droughts than before or after. Of 1932 large wildfires between 1984-2014 in cells affected by drought, 868 occurred in the three years preceding a drought, 820 occurred during, and 244 in the three years following. Fire size in drought pixels ranged up to 228687 ha, compared to maximum size of 66919 and 10790 ha before and after, respectively. The 95 th percentile of low- and moderate-severity burn fraction did not significantly differ from each other (KW test; $p>$ $0.05 ; p>0.05)$, while drought fires accounted for a $26.97 \%$ and $61.32 \%$ increase at the 95 th percentile of high-severity and total burn areas, respectively (KW test; $p<0.01 ; p<0.1$ ) (Fig. 6a). Fires in years following drought had greater moderate-severity area, while years prior to drought had greater low-severity area (Fig. 6a).

The 2009-16 tree mortality observations included coverage of all forested land within California. Half of California forests were included in drought cores for the 2012-14 period. Cores were concentrated within the higher elevations of the interior ranges with some extensions to the coastal ranges and Northern California redwood forests. Tree mortality was greater across
California following 2014 (KW test; $p<0.05$ ) (Fig. 6b). In the periods before, during, and after the 2012-14 drought, mortality was greater in drought-affected areas than other forest areas of the state (Dunn's test; $p<$ $0.05 ; p<0.05 ; p<0.05)$.

\section{Discussion}

Our results present current ecologically significant droughts in the context of similar events of the past century. Though average standardized precipitation anomalies were similar across all droughts (Fig. 3), there were more and greater precipitation extremes and temperature extremes in 2012-14 (Fig. 5a). Among the largest and most severe of the last century, the 2000-02 and 2012-14 droughts may be early analogs for climate-change-enhanced droughts of the twenty-first century, particularly in regions with historically greater snowpack (Cook et al. 2015). Physical topography could explain patterns of separated cores within a larger watershed, evident in the Great Basin between 2012 and 2014 (Fig. 3). Snow drought, in which substandard snowpack occurs as a result of less precipitation, or greater percentages of winter 
a) Wildfires in Drought Regions, 1984 to 2014

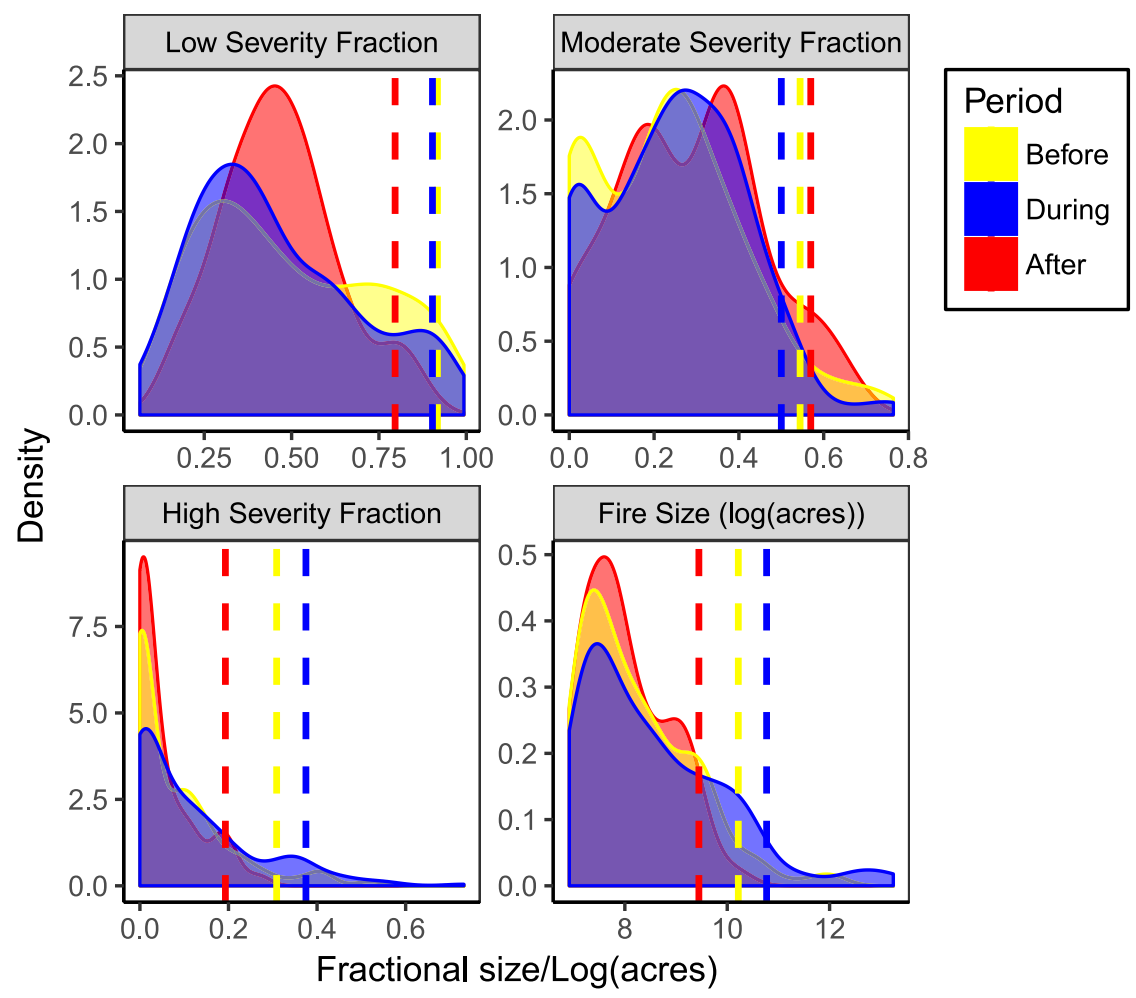

b) California Tree Mortality, 2009 to 2016

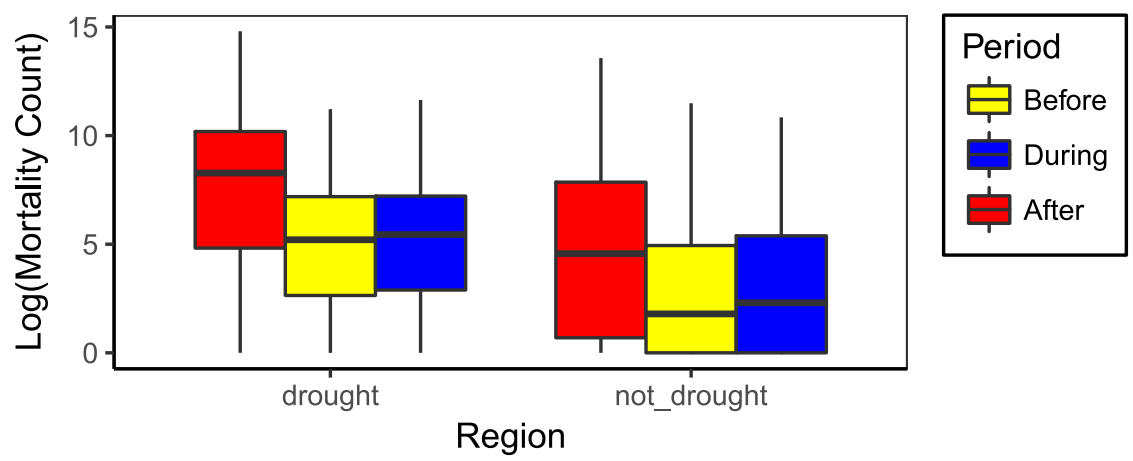

FIG. 6. (a) Recent drought effects on fire between 1984 and 2014 in the western United States and (b) California tree mortality between 2009 and 2016. Shown in (a) are fire size and severity fraction of fires in 3-yr periods before, during, and after droughts between 1984 and 2014, with the 95th percentile indicated by vertical lines. Severity is expressed as the fraction burned at a given severity in a fire and fire size is expressed as log-transformed burn acreage. Only nonmanagement fires that burned larger than 1000 acres were included. In (b), box plots are divided into period (colors) and drought/nondrought areas ( $x$ axis). The before period covers 2009-11, the during period covers 2012-14, and the after period covers 2015-16. The $y$ axis is expressed in terms of log- transformed counts of tree mortality.

precipitation falling as rain, has been presented as a concern in future hot droughts (Cooper et al. 2016). In conjunction with the analysis presented in Fig. 5, it appears that lower winter precipitation in particular increased the severity of the drought cores in this region.
Of critical concern to land managers are recent increasing fire size and severity and tree mortality linked to increasing temperatures and aridity (Miller and Safford 2012; van Mantgem et al. 2013; Westerling 2016; Keyser and Westerling 2017; Young et al. 2017). Our results support multiyear severe drought as a factor 
in increasing fire size and severity, as well as tree mortality. Increased prevalence of dead or desiccated fuels from direct and indirect drought effects (Mueller et al. 2005; Shaw et al. 2005; McDowell et al. 2008) is conducive to crown fires, which require ladder fuels to move from volatile grasses to the less volatile midlevel forest to the dry and volatile canopy cover (Van Wagner 1977). In nondrought years, fires may be smaller and less severe because midlevel vegetation does not ignite and spread into the canopy cover as easily as following multiple years of desiccation. Temporal limitations of the MTBS record require conclusions be drawn from a period with increased fire size and frequency (Westerling 2016), but recent droughts encompassed the largest WUS fires during the last 30 years.

Tree mortality in California forests is a visual indicator of drought to the public. The forests included here were fully within the larger regional 2012-14 drought area (e.g., elevated accumulated CWD shown in Fig. 3), though the drought cores predominantly affected interior forests. Consistent with global trends (Allen et al. 2010; van Mantgem et al. 2013; Anderegg et al. 2016), greater severity and, consequently, greater accumulated CWD in cores resulted in diverging mortality between core and noncore drought areas. Of interest is the lagged temporal relationship in both core and noncore areas (Fig. 6b). Because the fly-over observations used to generate these data did not differentiate between bark beetle mortality and mortality from hydraulic failure, we cannot confidently attribute this fully to a specific mechanism. However, the lagged temporal relationship between drought and tree mortality seen in Fig. 6 has been noted in other drought events, with mortality possible decades later (Bigler et al. 2007).

\section{Conclusions}

Here we employed an ecologically significant drought metric to characterize areas of intense drought in the WUS in the twentieth and twenty-first century. In summary, such droughts of the past 15 years were more intense than early to mid-twentieth-century droughts, with greater temperature and precipitation extremes contributing to extreme CWD over larger areas. Within areas of intense drought stress, wildfires were larger and more severe and were followed by extensive tree mortality. Climate projections anticipate warming temperatures for the next century, and although less certainty is attributed to projected changes in WUS precipitation, extreme high precipitation events may be separated by longer periods of aridity (Wuebbles et al. 2014). Land managers should anticipate droughts in the future similar to recent events and prepare for larger, more severe fires and greater tree mortality.

Acknowledgments. This research was supported by the California Nevada Applications Program under NOAA Grant NA110AR4310150, the USDA under the U.S. Forest Service Award 14-CS-11052006-025, and the California Energy Commission under Grant CEC-50014-004. We thank D. Cayan, J. Blois, H. Preisler, D. Lettenmaier, and A. Keyser for their thoughtful comments; J. Milostan for assistance in processing hydroclimate data; and Z. Heath and H. Preisler for ADS mortality data.

\section{REFERENCES}

Aalto, J., P. Pirinen, J. Heikkinen, and A. Venäläinen, 2013: Spatial interpolation of monthly climate data for Finland: Comparing the performance of kriging and generalized additive models. Theor. Appl. Climatol., 112, 99-111, https://doi.org/10.1007/ s00704-012-0716-9.

Allen, C. D., and Coauthors, 2010: A global overview of drought and heat-induced tree mortality reveals emerging climate change risks for forests. For. Ecol. Manage., 259, 660-684, https://doi.org/10.1016/j.foreco.2009.09.001.

Alley, W. M., 1984: The Palmer drought severity index: Limitations and assumptions. J. Climate Appl. Meteor., 23, 1100-1109, https://doi.org/10.1175/1520-0450(1984)023<1100: TPDSIL $>2.0 . \mathrm{CO} ; 2$.

Anderegg, W. R. L., and Coauthors, 2016: When a tree dies in the forest: Scaling climate-driven tree mortality to ecosystem water and carbon fluxes. Ecosystems, 19, 1133-1147, https:// doi.org/10.1007/s10021-016-9982-1.

Andreadis, K. M., E. A. Clark, A. W. Wood, A. F. Hamlet, and D. P. Lettenmaier, 2005: Twentieth-century drought in the conterminous United States. J. Hydrometeor., 6, 985-1001, https://doi.org/10.1175/JHM450.1.

Asner, G. P., P. G. Brodrick, C. B. Anderson, N. Vaughn, D. E. Knapp, and R. E. Martin, 2016: Progressive forest canopy water loss during the 2012-2015 California drought. Proc. Natl. Acad. Sci. USA, 113, E249-E255, https://doi.org/10.1073/ pnas.1523397113.

Ault, T. R., J. E. Cole, J. T. Overpeck, G. T. Pederson, and D. M. Meko, 2014: Assessing the risk of persistent drought using climate model simulations and paleoclimate data. J. Climate, 27, 7529-7549, https://doi.org/10.1175/JCLI-D-12-00282.1.

Bachmair, S., I. Kohn, and K. Stahl, 2015: Exploring the link between drought indicators and impacts. Nat. Hazards Earth Syst. Sci., 15, 1381-1397, https://doi.org/10.5194/nhessd-2-7583-2014. and Coauthors, 2016: Drought indicators revisited: The need for a wider consideration of environment and society. Wiley Interdiscip. Rev.: Water, 3, 516-536, https://doi.org/10.1002/ wat2.1154.

Bigler, C., D. G. Gavin, C. Gunning, and T. T. Veblen, 2007: Drought induces lagged tree mortality in a subalpine forest in the Rocky Mountains. Oikos, 116, 1983-1994, https://doi.org/ 10.1111/j.2007.0030-1299.16034.x.

Bivand, R. S., T. Keitt, and B. Rowlingson, 2017: rgdal: Bindings for the Geospatial Data Abstraction Library, version 1.2-8. $\mathrm{R}$ package, https://CRAN.R-project.org/package $=$ rgdal . 
Brönnimann, S., and Coauthors, 2009: Exceptional atmospheric circulation during the "Dust Bowl." Geophys. Res. Lett., 36, L08802, https://doi.org/10.1029/2009GL037612.

Cayan, D. R., M. D. Dettinger, S. A. Kammerdiener, J. M. Caprio, and D. H. Peterson, 2001: Changes in the onset of spring in the western United States. Bull. Amer. Meteor. Soc., 82, 399-415, https://doi. org/10.1175/1520-0477(2001)082<0399:CITOOS>2.3.CO;2.

Cook, B. I., R. L. Miller, and R. Seager, 2008: Dust and sea surface temperature forcing of the 1930s "Dust Bowl" drought. Geophys. Res. Lett., 35, L08710, https://doi.org/10.1029/ 2008GL033486.

—, R. Seager, and R. L. Miller, 2011: Atmospheric circulation anomalies during two persistent North American droughts: 1932-1939 and 1948-1957. Climate Dyn., 36, 2339-2355, https://doi.org/10.1007/s00382-010-0807-1.

_- J. E. Smerdon, R. Seager, and E. R. Cook, 2014: Pancontinental droughts in North America over the last millennium. J. Climate, 27, 383-397, https://doi.org/10.1175/ JCLI-D-13-00100.1.

, T. R. Ault, and J. E. Smerdon, 2015: Unprecedented 21st century drought risk in the American Southwest and central plains. Sci. $A d v$., 1, e1400082, https://doi.org/10.1126/ sciadv.1400082.

Cook, E. R., R. Seager, M. A. Cane, and D. W. Stahle, 2007: North American drought: Reconstructions, causes, and consequences. Earth-Sci. Rev., 81, 93-134, https://doi.org/10.1016/ j.earscirev.2006.12.002.

Cooper, M. G., A. W. Nolin, and M. Safeeq, 2016: Testing the recent snow drought as an analog for climate warming sensitivity of Cascades snowpacks. Environ. Res. Lett., 11, 084009, https:// doi.org/10.1088/1748-9326/11/8/084009.

Crausbay, S., and Coauthors, 2017: Defining ecological drought for the 21st century. Bull. Amer. Meteor. Soc., https://doi.org/ 10.1175/BAMS-D-16-0292.1, in press.

Creeden, E. P., J. A. Hicke, and P. C. Buotte, 2014: Climate, weather, and recent mountain pine beetle outbreaks in the western United States. For. Ecol. Manage., 312, 239-251, https://doi.org/10.1016/j.foreco.2013.09.051.

Diffenbaugh, N. S., D. L. Swain, and D. Touma, 2015: Anthropogenic warming has increased drought risk in California. Proc. Natl. Acad. Sci. USA, 112, 3931-3936, https://doi.org/10.1073/ pnas.1422385112.

Dinno, A., 2017: dunn.test: Dunn's Test of Multiple Comparisons Using Rank Sums, version 1.3.4. R package, https:// CRAN.R-project.org/package $=$ dunn.test .

Donat, M. G., A. D. King, J. T. Overpeck, L. V. Alexander, I. Durre, and D. J. Karoly, 2016: Extraordinary heat during the 1930s US Dust Bowl and associated large-scale conditions. Climate Dyn., 46, 413-426, https://doi.org/10.1007/ s00382-015-2590-5.

Eidenshink, J., B. Schwind, K. Brewer, Z.-L. Zhu, B. Quayle, and S. Howard, 2007: A project for monitoring trends in burn severity. Fire Ecol., 3, 3-21, https://doi.org/10.4996/ fireecology.0301003.

Ge, Y., T. Apurv, and X. Cai, 2016: Spatial and temporal patterns of drought in the continental U.S. during the past century. Geophys. Res. Lett., 43, 6294-6303, https://doi.org/10.1002/ 2016 GL069660.

Griffin, D., and K. J. Anchukaitis, 2014: How unusual is the 20122014 California drought? Geophys. Res. Lett., 41, 9017-9023, https://doi.org/10.1002/2014GL062433.

Guarín, A., and A. H. Taylor, 2005: Drought triggered tree mortality in mixed conifer forests in Yosemite National Park,
California, USA. For. Ecol. Manage., 218, 229-244, https:// doi.org/10.1016/j.foreco.2005.07.014.

Heyerdahl, E. K., P. Morgan, and J. P. Riser II, 2008: Multi-season climate synchronized historical fires in dry forests (16501900), northern Rockies, USA. Ecology, 89, 705-716, https:// doi.org/10.1890/06-2047.1.

Hijmans, R. J., 2016: raster: Geographic Data Analysis and Modeling, version 2.5-8. R package, https://CRAN.R-project.org/ package $=$ raster.

Hoerling, M., and A. Kumar, 2003: The perfect ocean for drought. Science, 299, 691-694, https://doi.org/10.1126/science.1079053.

_, X.-W. Quan, and J. Eischeid, 2009: Distinct causes for two principal U.S. droughts of the 20th century. Geophys. Res. Lett., 36, L19708, https://doi.org/10.1029/2009GL039860.

_, J. Eischeid, A. Kumar, R. Leung, A. Mariotti, K. Mo, S. Schubert, and R. Seager, 2014: Causes and predictability of the 2012 Great Plains drought. Bull. Amer. Meteor. Soc., 95, 269-282, https://doi.org/10.1175/BAMS-D-13-00055.1.

Howitt, R. E., J. Medellin-Azuara, D. MacEwan, J. R. Lund, and D. A. Sumner, 2014: Economic analysis of the 2014 drought for California agriculture. University of California, Davis, Center for Watershed Sciences Rep., 20 pp., https://watershed. ucdavis.edu/files/content/news/Economic_Impact_of_the_ 2014_California_Water_Drought.pdf.

Keyser, A. R., and A. L. Westerling, 2017: Climate drives interannual variability in probability of high severity fire occurrence in the western United States. Environ. Res. Lett., 12, 065003, https://doi.org/10.1088/1748-9326/aa6b10.

Liang, S., M. D. Hurteau, and A. L. Westerling, 2017a: Response of Sierra Nevada forests to projected climate-wildfire interactions. Global Change Biol., 23, 2016-2030, https://doi.org/ 10.1111/gcb.13544.

$\ldots, \ldots$, and $\_, 2017 \mathrm{~b}$ : Potential decline in carbon carrying capacity under projected climate-wildfire interactions in the Sierra Nevada. Sci. Rep., 7, 2420, https://doi.org/10.1038/ s41598-017-02686-0.

Liang, X., D. P. Lettenmaier, E. F. Wood, and S. J. Burges, 1994: A simple hydrologically based model of land surface water and energy fluxes for general circulation models. J. Geophys. Res., 99, 14 415-14 428, https://doi.org/10.1029/94JD00483.

Littell, J. S., D. McKenzie, D. L. Peterson, and A. L. Westerling, 2009: Climate and wildfire area burned in western U.S. ecoprovinces, 1916-2003. Ecol. Appl., 19, 1003-1021, https://doi.org/ 10.1890/07-1183.1.

Livneh, B., T. J. Bohn, D. W. Pierce, F. Munoz-Arriola, B. Nijssen, R. Vose, D. R. Cayan, and L. Brekke, 2015: A spatially comprehensive, hydrometeorological data set for Mexico, the U.S., and southern Canada 1950-2013. Sci. Data, 2, 150042, https://doi.org/10.1038/sdata.2015.42.

Lutz, J. A., J. W. van Wagtendonk, and J. F. Franklin, 2010: Climatic water deficit, tree species ranges, and climate change in Yosemite National Park. J. Biogeogr., 37, 936-950, https:// doi.org/10.1111/j.1365-2699.2009.02268.x.

McCabe, G. J., M. A. Palecki, and J. L. Betancourt, 2004: Pacific and Atlantic Ocean influences on multidecadal drought frequency in the United States. Proc. Natl. Acad. Sci. USA, 101, 4136-4141, https://doi.org/10.1073/pnas.0306738101.

McDowell, N., and Coauthors, 2008: Mechanisms of plant survival and mortality during drought: Why do some plants survive while others succumb to drought? New Phytol., 178, 719-739, https://doi.org/10.1111/j.1469-8137.2008.02436.x.

Miller, J. D., and H. D. Safford, 2012: Trends in wildfire severity: 1984 to 2010 in the Sierra Nevada, Modoc Plateau, and 
southern Cascades, California, USA. Fire Ecol., 8, 41-57, https://doi.org/10.4996/fireecology.0803041.

Mitchell, K. E., and Coauthors, 2004: The multi-institution North American Land Data Assimilation System (NLDAS): Utilizing multiple GCIP products and partners in a continental distributed hydrological modeling system. J. Geophys. Res., 109, D07S90, https://doi.org/10.1029/2003JD003823.

Monteith, J. L., 1965: Evaporation and environment. Symp. Soc. Exp. Biol., 19, 205-234.

Morgan, P., E. K. Heyerdahl, and C. E. Gibson, 2008: Multi-season climate synchronized forest fires throughout the 20th century, northern Rockies, USA. Ecology, 89, 717-728, https://oi.org/ 10.1890/06-2049.1.

MTBS, 2016: Data Access: Fire Level Geospatial Data. USDA Forest Service/U.S. Geological Survey, accessed 8 October 2016, https://mtbs.gov/direct-download.

Mueller, R. C., C. M. Scudder, M. E. Porter, R. Talbot Trotter III, C. A. Gehring, and T. G. Whitham, 2005: Differential tree mortality in response to severe drought: Evidence for longterm vegetation shifts. J. Ecol., 93, 1085-1093, https://doi.org/ 10.1111/j.1365-2745.2005.01042.x.

Parks, S. A., C. Miller, J. T. Abatzoglou, L. M. Holsinger, M.-A. Parisien, and S. Z. Dobrowski, 2016: How will climate change affect wildland fire severity in the western US? Environ. Res. Lett., 11, 035002, https://doi.org/10.1088/1748-9326/11/3/ 035002.

Pebesma, E. J., and R. S. Bivand, 2005: Classes and methods for spatial data in R. R News, No. 5(2), R Foundation, Vienna, Austria, 9-13, http://cran.r-project.org/doc/Rnews/.

Penman, H. L., 1948: Natural evaporation from open water, bare soil and grass. Proc. Roy. Soc. London, 193A, 120-145, https:// doi.org/10.1098/rspa.1948.0037.

Preisler, H. K., N. E. Grulke, Z. Heath, and S. L. Smith, 2017: Analysis and out-year forecast of beetle, borer, and droughtinduced tree mortality in California. For. Ecol. Manage., 399, 166-178, https://doi.org/10.1016/j.foreco.2017.05.039.

R Development Core Team, 2011: R: A Language and Environment for Statistical Computing. R Foundation for Statistical Computing.

Rajagopalan, B., E. Cook, U. Lall, and B. K. Ray, 2000: Spatiotemporal variability of ENSO and SST teleconnections to summer drought over the United States during the twentieth century. J. Climate, 13, 4244-4255, https://doi.org/10.1175/ 1520-0442(2000)013<4244:SVOEAS >2.0.CO;2.

Robeson, S. M., 2015: Revisiting the recent California drought as an extreme value. Geophys. Res. Lett., 42, 6771-6779, https:// doi.org/10.1002/2015GL064593.

Routson, C. C., C. A. Woodhouse, J. T. Overpeck, J. L. Betancourt, and N. P. McKay, 2016: Teleconnected ocean forcing of western North American droughts and pluvials during the last millennium. Quat. Sci. Rev., 146, 238-250, https://doi.org/ 10.1016/j.quascirev.2016.06.017.

Schubert, S. D., M. J. Suarez, P. J. Pegion, R. D. Koster, and J. T. Bacmeister, 2004: On the cause of the 1930s Dust Bowl. Science, 303, 1855-1859, https://doi.org/10.1126/ science.1095048.

Seager, R., and M. Hoerling, 2014: Atmosphere and ocean origins of North American droughts. J. Climate, 27, 4581-4606, https://doi.org/10.1175/JCLI-D-13-00329.1.

Shaw, J. D., B. E. Steed, and L. T. DeBlander, 2005: Forest inventory and analysis (FIA) annual inventory answers the question: What is happening to pinyon-juniper woodlands? J. For., 103, 280-285.
Steinemann, A. C., 2014: Drought information for improving preparedness in the western states. Bull. Amer. Meteor. Soc., 95, 843-847, https://doi.org/10.1175/BAMS-D-13-00067.1.

—, M. J. Hayes, and L. F. N. Cavalcanti, 2005: Drought indicators and triggers. Drought and Water Crises: Science, Technology, and Management Issues, D. A. Wilhite, Ed., CRC Press, 71-92.

Stephenson, N. L., 1990: Climatic control of vegetation distribution: The role of the water balance. Amer. Nat., 135, 649-670, https://doi.org/10.1086/285067.

, 1998: Actual evapotranspiration and deficit: Biologically meaningful correlates of vegetation distribution across spatial scales. J. Biogeogr., 25, 855-870, https://doi.org/10.1046/ j.1365-2699.1998.00233.x.

Teng, H., and G. Branstator, 2017: Causes of extreme ridges that induce California droughts. J. Climate, 30, 1477-1492, https:// doi.org/10.1175/JCLI-D-16-0524.1.

Udall, B., and J. Overpeck, 2017: The twenty-first century Colorado River hot drought and implications for the future. Water Resour. Res., 53, 2404-2418, https://doi.org/10.1002/ 2016WR019638.

van Mantgem, P. J., and N. L. Stephenson, 2007: Apparent climatically induced increase of tree mortality rates in a temperate forest. Ecol. Lett., 10, 909-916, https://doi.org/10.1111/ j.1461-0248.2007.01080.x.

— , and Coauthors, 2009: Widespread increase of tree mortality rates in the western United States. Science, 323, 521-524, https://doi.org/10.1126/science.1165000.

— J. C. B. Nesmith, M. Keifer, E. E. Knapp, A. Flint, and L. Flint, 2013: Climatic stress increases forest fire severity across the western United States. Ecol. Lett., 16, 1151-1156, https://doi.org/10.1111/ele.12151.

Van Wagner, C. E., 1977: Conditions for the start and spread of crown fire. Can. J. For. Res., 7, 23-34, https://doi.org/10.1139/ $\mathrm{x} 77-004$.

Wang, S.-Y., L. Hipps, R. R. Gillies, and J.-H. Yoon, 2014: Probable causes of the abnormal ridge accompanying the 20132014 California drought: ENSO precursor and anthropogenic warming footprint. Geophys. Res. Lett., 41, 3220-3226, https:// doi.org/10.1002/2014GL059748.

Weiss, J. L., C. L. Castro, and J. T. Overpeck, 2009: Distinguishing pronounced droughts in the southwestern United States: Seasonality and effects of warmer temperatures. J. Climate, 22, 5918-5932, https://doi.org/10.1175/2009JCLI2905.1.

Westerling, A. L., 2009: Wildfires. Climate Change Science and Policy, S. H. Schneider et al., Eds., Island Press, 92-103.

- 2016: Increasing western US forest wildfire activity: Sensitivity to changes in the timing of spring. Philos. Trans. Roy. Soc. London, 371B, 20150178, https://doi.org/10.1098/ rstb.2015.0178.

, A. Gershunov, T. J. Brown, D. R. Cayan, and M. D. Dettinger, 2003: Climate and wildfire in the western United States. Bull. Amer. Meteor. Soc., 84, 595-604, https://doi.org/ 10.1175/BAMS-84-5-595.

, H. G. Hidalgo, D. R. Cayan, and T. W. Swetnam, 2006: Warming and earlier spring increases western U.S. forest wildfire activity. Science, 313, 940-943, https://doi.org/10.1126/ science.1128834.

—, M. G. Turner, E. A. H. Smithwick, W. H. Romme, and M. G. Ryan, 2011a: Continued warming could transform greater Yellowstone fire regimes by mid-21st century. Proc. Natl. Acad. Sci. USA, 108, 13 165-13170, https://doi.org/10.1073/ pnas. 1110199108 . 
B. P. Bryant, H. K. Preisler, T. P. Holmes, H. G. Hidalgo, T. Das, and S. R. Shrestha, 2011b: Climate change and growth scenarios for California wildfire. Climatic Change, 109, 445463, https://doi.org/10.1007/s10584-011-0329-9.

Wickham, H., 2007: Reshaping data with the reshape package. J. Stat. Software, 21, 1-20, https://doi.org/10.18637/jss.v021.i12. , 2009: ggplot2: Elegant Graphics for Data Analysis. Springer, 213 pp., https://doi.org/10.1007/978-0-387-98141-3.

— lation, version 0.5.0. R package, https://CRAN.R-project.org/ package $=$ dplyr.

Williams, A. P., and Coauthors, 2013: Temperature as a potent driver of regional forest drought stress and tree mortality. Nat. Climate Change, 3, 292-297, https://doi.org/10.1038/ nclimate1693.

Wood, A. W., and D. P. Lettenmaier, 2006: A test bed for new seasonal hydrologic forecasting approaches in the western
United States. Bull. Amer. Meteor. Soc., 87, 1699-1712, https:// doi.org/10.1175/BAMS-87-12-1699.

Wood, S. N., 2006: Generalized Additive Models: An Introduction with $R$. CRC Press, $410 \mathrm{pp}$.

_ 2011: Fast stable restricted maximum likelihood and marginal likelihood estimation of semiparametric generalized linear models. J. Roy. Stat. Soc., 73B, 3-36, https://doi.org/ 10.1111/j.1467-9868.2010.00749.x.

Wuebbles, D., and Coauthors, 2014: CMIP5 climate model analyses: Climate extremes in the United States. Bull. Amer. Meteor. Soc., 95, 571-583, https://doi.org/10.1175/ BAMS-D-12-00172.1.

Young, D. J. N., J. T. Stevens, J. M. Earles, J. Moore, A. Ellis, A. L. Jirka, and A. M. Latimer, 2017: Long-term climate and competition explain forest mortality patterns under extreme drought. Ecol. Lett., 20, 78-86, https://doi.org/10.1111/ ele.12711. 